\title{
建筑电气防雷接地设计要点浅析
}

\author{
王春华 \\ 新疆维吾尔自治区建筑设计研究院有限公司 \\ DOI:10.32629/btr.v3i7.3262
}

\begin{abstract}
[摘要] 随着我国科技技术不断发展和进步, 对建筑电气的设计的各方面要求也随着人们的要求和认 识在不断提升。对于建筑物来说, 防雷接地设计是一项非常重要的工作, 其设计质量的好坏直接影响着整 个建筑物能否安全地使用。为了防止雷击事故的发生, 必须要了解防雷接地装置可能出现的最大电位, 在设计中采取相应的措施。本文就对建筑物的防雷接地设计做出一些相关经验的总结和分析, 同时也为 此类设计做出系列的参考借鉴。
\end{abstract}

[关键词] 建筑电气; 防雷接地; 设计要点

中图分类号：TU856 文献标识码：A

在社会文明高速发展的过程中, 人 类的城市化进程不断的向前推动, 高层 建筑的需求也增多, 同时也带来了安全 隐患问题。为了保障住宅建筑中的居民 生命财产安全, 做好防雷接地工程设计, 对于降低雷电灾害对建筑物的危害性至 关重要。

\section{1 建筑电气防雷接地系统简述}

建筑电气防雷接地系统主要有引下 线、防雷装置以及接地装置等, 其中防雷 装置主要包括内部雷电防护装置与外部 雷电防护装置, 引下线的使用需要与接 闪杆、接闪带等结合使用, 主要是把雷电 流向接地装置传导。接地装置主要是用 于传导雷电流, 并在此基础上将其流入 大地。此外, 等电位连接一般情况下是对 装置与导电物体的有效连接, 以此有效 避免雷电对用电设备和人员的损害, 其 中接地系统主要分为工作接地、防雷接 地以及保护接地, 防雷接地还具有使建 筑物保持等电位的作用, 在对接地系统 设计的过程中, 防雷击系统在其中尤为 重要, 这就需要提高建筑接地系统设计 质量。

\section{2 建筑电气防雷接地的重要} 意义

建筑电气防雷接地对于建筑使用者 而言十分重要, 因为雷击的瞬间通常会 达到几十甚至几百千伏, 无论是建筑本
身还是建筑中的电气电子设备都无法承 受如此高的电压, 会直接损坏电气及电 子系统。建筑物本身所具有的钢筋也会 成为天然导体, 并最终形成雷电流, 进 出建筑物的各种线路及金属管道将导 致雷电波的侵入, 对建筑内部环境产生 巨大的威胁。建筑电气防雷接地的作用 就是防范和消除这些危害, 使建筑物及 内部的电气电子设备形成等电位均压 和多层屏蔽的安全防雷结构, 保证建筑 整体安全。

\section{3 建筑防雷接地相关介绍}

建筑防雷装置上主要由两个部分组 成, 其中一个部分是外部雷电防护装置, 这一装置的基本构件主要有三样, 分别 是: 引下线、接地装置以及接闪器, 主要 的作用就是防止直击雷, 从而保护建筑 安全。另外一个部分为内部雷电防护装 置, 这一部分的基本构件主要有: 等电位 连接、合理布线、屏蔽系统以及电涌保 护器。

3. 1 接闪器

接闪器可以由避雷带、避雷针或者 针带组成, 是防雷接地系统中的避雷组 件, 接闪器的安装位置分布在沿房角、房 脊、房檐等容易受到雷击的地方, 建筑上 的接闪器要同引下线焊接相连通, 它的 功能和作用是, 建筑上的接闪器要同引 下线焊接相连通。当雷电来临时候, 可以
最大概率和限度地将雷电第一时间引向 自身的接闪设备, 在接受雷击后并进行 放电。

\section{2 引下线}

通常情况下, 使用引下线时需要结 合接闪器共同作用的, 其主要功能是充 当导线体部分, 将电击形成的电流在通 过引下线后引入到地下。该部分对于材 料的选择有着非常高的要求, 必须选择 在性能上能够有较强的耐腐蚀性, 且兼 有较强的机械性能。

\section{3 等电位连接}

等电位连接主要是将导电物和装置 相互连接起来的导体, 其主要作用是使 导电物与装置两者之间的电位差减少, 从而让接地装置受到雷击后的损坏强度 能够降低。

3. 4 接地

现阶段在建筑电气防雷接地设计中, 主要会选择两种防雷接地方式, 其中一 种是功能性防雷接地; 另外一种是保护 性防雷接地。两种是不同的接地方式保 护的对象不同, 功能性防雷接地装置主 要是保护建筑内部的设备, 保护性防雷 接地装置主要是保护人的安全。

\section{4 关于建筑电气防雷接地设计 的要点 \\ 防雷接地在建筑电气接地系统设计 中是一项非常重要的环节。一般建筑物}


的防雷保护主要分为一类、二类、三类 这三种类型的级别。在民用建筑过程中, 大部分都会采用二类的防雷保护措施。 当建筑内部中存在爆炸危险的话, 就应 该采用一类的防雷保护措施来进行设 计。以下就建筑电气防雷接地设计的要 点进行分析:

4. 1直击性雷电防雷设计要点

4. 1. 1直击性雷电防雷设计主要是 合理的利用好接闪杆和接闪网。通过科 学合理的设计, 最大限度的获得避雷、防 雷效果。当然, 还可以利用一些金属设备, 主要起到一个接闪的作用, 只要是符合 规范标准, 就能发挥出一定作用。

4.1.2要把握好电气防雷接地设计 中地下引线的设计。要综合考虑建筑物 内的设施, 掌握电位的有关数据, 使整个 引下线成为一个整体, 相互连接。

4. 1.3 重视基础性设计。直击性雷电 防雷设计中, 打好基础是非常关键的。要 认真做好每个工作细节, 符合钢筋混凝 土的建筑特点, 合理布置接地线路, 使其 在防雷上发挥出最大的作用。建筑电气 防雷接地设计的时候, 直击性雷电是在 实际情况中相对普遍的一个问题, 所以 直击性雷电防雷设计是建筑电气防雷接 地设计中非常重要的一项内容。

4. 2 防侧雷击的设计要点

对于建筑物而言, 顶部防雷装置的 设置并不能全面的保护建筑物安全, 侧 面雷击事故会对建筑产生严重危害, 所 以建筑防雷接地设计中防侧击雷的设计 是必需的内容。防侧击雷的设计要点可 以从以下几个方面进行考虑:

4.2.1建筑物各层结构圈梁内的钢 筋需要全部连接为闭合回路, 并与作为 防雷引下线的混凝土柱内坚向钢筋连接, 保证发生雷击时, 建筑物内的横坚向钢

筋可以形成一个完整的电气通路。

4.2.2建筑物内所有的钢构件均与 钢筋混凝土中的钢筋相互连接, 高层建 筑60米以上每隔2层做均压环, 外墙上的 栏杆、金属门窗等较大金属物直接或通 过金属门窗埋铁与均压环相连。

4. 3 选用材料比较好的防雷导线 装置

目前, 在我国已有明文规定, 当雷电 最低的时候与地面的距离不能超过一定 的高度, 任何建筑物在超过这个高度之 后, 都要对其做相应的电气防雷接地设 计。因此, 在楼层数比较多的建筑的电气 防雷接地设计过程中, 首先要建好避雷 网, 当建筑物一旦遇到突发情况受到雷 击时, 雷电会沿着接引装置流入接地装 置中, 并且要很好的运用高层建筑在空 间和结构上的长处, 来充分发挥其避雷 网的作用。在高层建筑物的电气防雷接 地设计时, 必须要选用符合国家规定, 质 量好的电缆等配线装置, 进而来提高建 筑物电气防雷接地设计的总体质量。

4. 4 合理设置防雷设计中接闪器

高层建筑物内部构造当中都有主要 的钢筋作为支撑, 这时候要想使接地装 置正常运行需要以此作为桥梁进行设 计。一旦受到雷电侵害的时候, 电流便会 通过引下线汇入到接地装置当中去, 实 现电流的正常释放, 避免产生不必要的 财产损失以及人员伤亡。当然这个过程 并不是简单地设置和安装, 而是需要专 业的设计人员根据建筑物的具体布局和 构造进行科学设计。

\section{5 合理的屏蔽措施}

建筑物纵向布置的电线或电缆宜敷 设在屏蔽的强弱电专用坚井中, 各层段 竖井的接头处应紧密相接, 使其接触电 阻尽可能小, 以保证坚井的屏蔽效果。坚
井的平面位置理论上最好布置在建筑物 的中心, 因为中心的电磁场最弱, 而实际 工程中, 大多位于电梯井道两侧和楼梯 走道两侧。想要更好地实现对住宅建筑 的防雷防电干扰, 还需要对其电子设备 以及电气线路实施非常科学合理的屏蔽 处理。由于建筑物的电气主干线通常情 况下都是沿着其电气坚井来实施铺设的, 在电坚井内敷设一条接地干线 (可为 40x4铜排), 其下端应与接地网可靠连 接。金属线槽与各个楼层之间的等电位 联结板或接地母线进行有效的连接。

\section{5 结语}

随着全国城市化的高速发展, 在建 筑设计中合理地使用防雷系统保护措施 不但能够确保配电系统的安全, 而且可 以更好地维护国民的生活。把防雷接地 设计同建筑物的构造形式有效的结合起 来, 充分地考虑好设计工作中的重点和 难点部分, 对雷电危害产生的各种问题 做好科学、合理的估计和预防, 让建筑物 能有效地避免雷电灾害的影响, 提高建 筑物的安全实用性能, 给人类的日常生 活提供良好的保障。

\section{[参考文献]}

[1]李品兴.建筑电气设计方案分析 [J].科学技术创新,2018,(25):68-69.

[2]袁志和.高层建筑电气设计中的防 雷技术[J].住宅与房地产,2018,(18):86+95.

[3] 曾伟超, 陈新东. 建筑电气防 雷接地设计方式研究 [J]. 住宅与房地 产,2018,(16):98.

[4]谭栋梁.建筑防雷接地系统设计 及要点[J].科技与创新,2016,(3):108-109.

[5]刘达华,朱英彩, 谭健辉. 高层住 宅建筑防雷接地设计探讨 [J]. 科技展 望,2016,26(03):38 